\title{
O professor universitário como agente letrador: interfaces com o desenvolvimento do letramento acadêmico
}

\author{
Dalve Oliveira Batista-Santos ${ }^{1}$ \\ Colegiado de Letras/Programa de Pós-Graduação em Letras, \\ Universidade Federal do Tocantins, Porto Nacional, TO, Brasil.
}

Resumo: O objetivo central deste estudo, inserido na área da Linguística Aplicada, é investigar a atuação do professor enquanto agente de letramento (KLEIMAN, 2006) na universidade, com a finalidade de compreender de que forma este agente faz a mediação e o gerenciamento das diferentes vozes numa atividade dialógica de construção de sentidos. Para tanto, esta pesquisa tem orientação interpretativista e utilizou-se da metodologia do Pensar Alto em Grupo-PAG (Cf. ZANOTTO, 1995). A fundamentação teórica relaciona-se aos pressupostos dialógicos do Círculo de Bakhtin e às pesquisas desenvolvidas segundo os pressupostos teórico-metodológicos dos Novos Estudos do Letramento. Os dados revelaram que: a) nas ações (refutando, acatando, ampliando ideias) das participantes, o desenvolvimento do letramento acadêmico foi se constituindo à medida que faziam as leituras críticas, por meio de seus posicionamentos no processo de construção de sentidos; b) a professora foi se constituindo agente letradora, à medida que gerenciava e mediava as vozes das participantes.

Palavras-chave: Agente Letrador; Letramento Acadêmico; Universidade.

Title: Professors as literacy agents: interfaces with the development of academic literacy

Abstract: The main objective of this study, situated within Applied Linguistics field, is to investigate the role of the teacher as a literacy agent (KLEIMAN, 2006) at the university, in order to understand how this agent mediates and manages the different voices in a dialogical activity of meaning making. To do so, this research has an interpretative orientation and was based on the methodology of Group Think Aloud (GTA) (Cf. ZANOTTO, 1995). The theoretical foundation is related to the dialogical assumptions of Bakhtin circle, and to studies developed according to the theoretical and methodological assumptions of New Literacy Studies. Data revealed that: a) in the actions (refuting, accepting, broadening participants' ideas), participants' development of academic literacy came to take place as they made some critical readings, through their stances towards the process of meaning making; $b$ ) the professor turned out to be a literacy agent, as she managed and mediated participants' voices.

Keywords: Literacy agent; Academic Literacy; University.

\footnotetext{
1 Doutora em Linguística Aplicada e Estudos da Linguagem (PUC/SP), Professora Adjunta da Universidade Federal do Tocantins, lotada no Colegiado de Letras-Língua Portuguesa e Docente Permanente do Programa de Pós-Graduação em Letras. UFT de Porto Nacional. Orcid: http://orcid.org/0000-0002-9133-3446

E-mail: dalve@uft.edu.br
} 


\section{Considerações iniciais}

Algumas pesquisas (LEA; STREET, 2014; FIAD, 2011; BATISTA-SANTOS, 2017), nos últimos anos, passaram a debruçar-se sobre a questão do letramento acadêmico, isto é, de práticas de leitura e de escrita de estudantes do ensino universitário. Essas pesquisas têm demonstrado que os alunos ingressantes em cursos de graduação possuem preocupantes dificuldades na leitura e produção de gêneros textuais diversos, especificamente os acadêmicos (resumos, resenhas, artigos científicos, dissertações etc.).

Tais dificuldades, em tese, não deveriam ter ultrapassado o Ensino Médio, considerando as competências e habilidades estabelecidas pelos documentos que regem esta modalidade de ensino, os PCN - Ensino Médio. Esse fato nos leva a questionar os saberes cristalizados que surgem como 'pedagogias dominantes' de maneira naturalizada, como a do modelo autônomo de letramento - "concepção endêmica do letramento pedagogizado" (STREET, 2014, p. 130) -, em detrimento de atitudes que objetivam uma concepção alternativa, ou, nas palavras de Street (2014), um modelo ideológico de letramento. Tal naturalização é considerada preocupante ou perigosa em qualquer processo intelectual.

Nesse contexto, temos um novo perfil de aluno - uma vez que não é o esperado pela maioria dos docentes (comprovado na pesquisa de BATISTA-SANTOS, 2017) - o que requer novos modos de produzir conhecimentos e projetos de currículo que sejam capazes de atender às necessidades dos estudantes, ou seja, que leve em conta seu contexto real. Considerando esse novo perfil e a necessidade de incluir esses alunos na nova esfera social (modelo da socialização acadêmica, LEA; STREET, 2014), o presente texto ${ }^{2}$ apresenta uma investigação acerca da atuação do professor enquanto agente de letramento (KLEIMAN, 2006) $)^{3}$ na universidade, com a finalidade de compreender de que forma este agente faz a mediação e o gerenciamento das diferentes vozes numa atividade dialógica de construção de sentidos.

Para tanto, utilizamos a metodologia do Pensar Alto em Grupo - PAG (ZANOTTO, 1995). O PAG é uma vivência pedagógica de leitura, que permite ao educando um posicionamento legítimo na construção de suas múltiplas leituras (sentidos) e, consequentemente, desenvolvimento do Letramento Acadêmico. Assim, vinculado ao Grupo de Estudos da Indeterminação e da Metáfora - GEIM/CNPq, este texto discorre, primeiramente, acerca do Letramento Acadêmico. Na sequência, evidencia a seção metodológica e a análise e discussão dos dados.

\footnotetext{
${ }^{2}$ Texto recorte das investigações que compõem a tese de Doutorado da autora, que trata de outras discussões sobre a prática dialógica de leitura na esfera acadêmica. Pesquisa desenvolvida com apoio financeiro da CAPES.

${ }^{3}$ Para Kleiman o agente de letramento é "um promotor das capacidades e recursos de seus alunos e suas redes comunicativas para que participem das práticas sociais de letramento, as práticas de uso da escrita situadas, das diversas instituições" (KLEIMAN, 2006, p. 08).
} 


\section{Letramento Acadêmico}

A abordagem sociocultural (GEE, 1999, 2000; STREET, 2014; LEA; STREET, 2014), na qual o presente artigo se fundamenta, entende o letramento num sentido plural do termo, sendo Letramentos. Assim, Letramento enquanto um fenômeno "[...] é compreendido como um conjunto de práticas sociais e associado com diferentes domínios de vida" (BARTON; HAMILTON, 2000, p. 8). Dessa maneira, as atividades de leitura, escrita e a construção de sentidos são concretizadas em práticas sociais situadas e específicas (GEE, 2000) - no caso da presente pesquisa - na esfera acadêmica. Esses sentidos, na perspectiva de Gee (2000), permitem identificar, no cerne dessas práticas sociais, posicionamentos dos sujeitos envolvidos (alunos e professores), relações de poder e de autoridade que concebem esses sujeitos sociais ora como insiders (membros efetivos) ora como outsiders (membros não engajados) nessas práticas.

Partindo dessa concepção de letramento - práticas sociais situadas - pesquisada no interior dos NEL, alguns pesquisadores (Cf. STREET, 2014; LEA; STREET, 2014) começaram a focar o contexto universitário, com a finalidade de entender as práticas dessa esfera, defendendo que existem práticas específicas nesse ambiente, dada a abordagem de múltiplos letramentos. Esse enfoque dado aos estudos do letramento na esfera acadêmica ganhou uma proporção significativa em diversas esferas de pesquisa, não apenas pelo caráter subjacente à concepção de letramentos múltiplos, mas sobretudo por motivações sociais e políticas, evidenciando-se o apogeu da Educação Superior, não apenas em um quantitativo de discentes, mas também em multiplicidade linguística e cultural. Essa concepção dos estudos dos NEL, que teve sua gênese no Reino Unido, é caracterizada e definida como Letramentos Acadêmicos.

Essa vertente de letramento, nos remete, de imediato, ao modelo ideológico, que é essencial nas práticas dialógicas de linguagem. O modelo ideológico de letramento é imprescindível, pois na contemporaneidade não seria mais concebível pesquisas acerca das práticas de leitura e da escrita, com enfoque nos elementos linguísticos, sem uma concepção crítica, social e responsiva, uma perspectiva engajada e situada numa abordagem etnográfica e uma inclusão sociocultural das dimensões discursivas (MARCUSCHI, 2002).

As relações sociais se mantêm e evoluem por meio das práticas de letramentos em seus diversos contextos, o que demonstra o fato de que a leitura e a escrita estão presentes em todas as interações humanas. Compreende-se, dessa maneira, que todo universitário possui algum tipo de saber sobre a leitura e a escrita que possibilita sua atuação na academia. Contudo, no contexto acadêmico, a leitura e a escrita se apresentam com finalidades específicas para tal esfera social, sem desconsiderar as relações de letramento construídas pelos sujeitos ao longo da vida acadêmica. Os saberes adquiridos pelos sujeitos nas modalidades de ensino anteriores (Ensino Fundamental e Médio, por exemplo) não devem ser desconsideradas na passagem de uma esfera social para outra. 
Ao tomar o conceito de Letramento como a relação de utilização que um sujeito ou uma comunidade firma com a escrita e a leitura, torna-se um equívoco a ideia do sujeito iletrado, pois ao contrário do que pensam muitos professores universitários sobre a escrita dos alunos, tais estudantes são letrados e, muito possivelmente, não se engajaram ainda nas práticas letradas que são esperadas no contexto da academia (BATISTA-SANTOS, 2017). Assim, por não terem se engajado, ainda, esses estudantes não podem ser considerados iletrados, por não conhecerem e dominarem as práticas sociais de utilização da linguagem, sobretudo na esfera universitária.

Nessa "nova esfera social", as práticas que envolvem a leitura e a escrita serão compreendidas como um processo complexo, o que requererá uma dinâmica diferenciada por parte dos sujeitos envolvidos, pois exigirá novas atitudes, novas maneiras de apreender e expor os saberes, novos modos, novas maneiras de se expressar por meio dos gêneros textuais que circulam e que são próprios da esfera acadêmica. Acerca dos gêneros textuais, vale dizer que, na concepção de Marcuschi (2002, p. 19), "os gêneros textuais são fenômenos históricos, profundamente vinculados à vida cultural e social", o que dialoga com a concepção de Letramento defendida pelos NEL.

Sendo assim, apreendemos uma relação de reciprocidade entre gêneros e letramento nas múltiplas interações verbais, visto que os gêneros textuais são os instrumentos de que os sujeitos fazem uso em um dado momento e ambiente, e o letramento corresponde aos saberes de como usá-los de maneira significativa no referido contexto. Logo, é presumível que, para que os estudantes se insiram nas práticas de leitura e escrita dos gêneros acadêmicos, 0 Letramento Acadêmico, nenhum espaço será melhor do que a própria universidade.

Conforme Lea e Street (2014), é possível avaliar o Letramento Acadêmico por meio da observação da escrita - e, podemos afirmar, por meio da leitura também - dos estudantes que provêm de classes sociais e etnias distintas. Quando ingressam na universidade, esses alunos são solicitados a produzir e ler gêneros diferentes, gêneros com os quais não estão familiarizados nas práticas de escrita e de leitura. Essa não familiarização é consequência de práticas cristalizadas que não consideram o contexto anterior dos acadêmicos, o que gera uma 'má' avaliação de suas capacidades e produções (orais e escritas) por parte dos professores. Os autores explicam ainda que, nesse contexto, passa a se tornar evidente o conflito entre o que é esperado por parte dos professores em relação às produções orais e escritas e o que efetivamente os alunos apresentam. No contexto universitário, geralmente não são reconhecidos tipos diferentes de letramentos, considerando a variabilidade de perfis dos alunos e, assim, relegam-se os sujeitos à condição de iletrados para a universidade.

O Letramento Acadêmico considera todo o contexto sócio-histórico dos alunos universitários e não encara o sujeito como iletrado, sendo a universidade, para ele, uma fonte a mais de apropriação de novos letramentos. Assumir como base o Letramento Acadêmico é algo relevante para todos os envolvidos nesse processo, sobretudo por considerar as representações que alunos, professores e instituição atrelam à escrita, além de partir das 
questões epistemológicas que abarcam as relações de poder estabelecidas entre os sujeitos no que tange ao uso de tal modalidade da língua.

Fiad (2011) - apoiada nas reflexões sobre o Letramento Acadêmico - faz uma releitura de textos produzidos há mais de duas décadas, por alunos universitários, na tentativa de aproximar as reflexões feitas por esses alunos e as reflexões dos estudos que debatem o ensino da escrita no âmbito acadêmico, especialmente quando consideram os alunos como sujeitos letrados e iniciantes nas práticas letradas acadêmicas que, até o momento, lhes eram desconhecidas. Em seus achados, ao avaliar essas produções, a referida autora observa alguns aspectos da escrita produzida na universidade, que chamam mais a atenção do estudante, quando esse se torna mais reflexivo sobre essa escrita. Observa ainda que, em relação à organização e à clareza dos textos, há uma manutenção de informações genéricas e vagas.

Como síntese de seus resultados, a autora deixa uma questão em aberto sobre a escrita na universidade, - que podemos levar para o ensino de leitura também - dizendo que "[...] fica a suspeita de que nem todos os mistérios na prática da escrita [e leitura] podem deixar de existir. Se, por um lado, é um caminho a ser perseguido nas práticas de ensino da escrita [e da leitura], por outro, é algo inatingível" (FIAD, 2011, p. 367).

Assim, se, em outras épocas, era possível enxergar o desempenho da escrita como uma habilidade individual de leitura e escrita, adquiridas especialmente na educação básica, na contemporaneidade é preciso situar essas práticas que envolvem a leitura e a escrita em um contexto mais amplo, relacionado a elementos sociais, históricos e culturais específicos de cada sujeito.

Falar, portanto, sobre Letramento Acadêmico envolve tratar dos estudos que abordam a área dos NEL. Street (2003) propõe que as práticas de letramento são práticas essencialmente sociais, com sentidos situados/contextualizados, em distintas instituições e grupos sociais. O Letramento Acadêmico assume que tais práticas de utilização da escrita e da leitura diferem-se em usos, como por exemplo, os gêneros textuais: resumo acadêmico e resumo escolar. Conforme o contexto em que esses gêneros se apresentam, teremos uma forma diferente de escrita e leitura, isto é, no resumo acadêmico teremos uma linguagem científica, o que não é cobrado no resumo escolar.

Diante deste fato, é possível falarmos sobre o Letramento Acadêmico, especialmente quando se assume que existem usos específicos da escrita e da leitura no contexto universitário que diferem de outros contextos (STREET, 2003; BARTON, 2007; GEE, 2004). Para Lea e Street (1998, p. 157), "a aprendizagem no ensino superior implica a adaptação a novas formas de saber: novas maneiras de compreender, interpretar e organizar o conhecimento". Assim, o alinhamento com a perspectiva do modelo ideológico conduz a uma visão de que as práticas sociais de letramento, nas quais os acadêmicos estão envolvidos, são entendidas a partir de três perspectivas ou modelos principais, quais sejam: estudo das habilidades, socialização acadêmica e letramento acadêmico.

A primeira dessas perspectivas - estudo das habilidades - envolve o letramento na 
qualidade de conjunto de habilidades individuais e cognitivas que os estudantes devem adquirir e desenvolver e que podem transferir para os distintos contextos universitários. Compreender o letramento tão somente no bojo desse modelo desconsidera a trajetória anterior de letramento do aluno, atribuindo a ele a responsabilidade de desenvolver competências cognitivas e metacognitivas de leitura e escrita para incluir-se no contexto universitário, de forma que qualquer fracasso no uso das competências escritoras e leitoras nesse contexto se torna de total responsabilidade do aluno.

Lea e Street (2014) prosseguem dizendo que a socialização acadêmica, por sua vez, parte da premissa de que o docente é considerado responsável por inserir os alunos na cultura universitária, fazendo com que eles assimilem as formas de falar, pensar, interpretar e saibam fazer uso das práticas de escrita que orbitam no campo acadêmico. Tal princípio envolve a concepção de que os gêneros textuais acadêmicos são relativamente homogêneos e, portanto, quando o aluno aprende suas convenções, habilita-se às práticas letradas que envolvem esse contexto. Para Lea e Street (2014), tal modelo parte da hipótese de que o âmbito acadêmico é imutável e suas identidades são facilmente visíveis, o que significa que, uma vez apreendidos os gêneros acadêmicos específicos das disciplinas, os alunos são capacitados para reproduzilos perpetuamente, sem maiores problemas.

Conforme Lea e Street (2014), quando se aborda do ponto de vista do Letramento Acadêmico (influenciado pela linguística crítica e social), compreendem-se os múltiplos letramentos que envolvem a instância universitária na qualidade de prática social. Dessa forma, o modelo de letramento acadêmico pode ser caracterizado pela concentração nos sentidos que alunos, professores e universidade atrelam à escrita e à leitura, tomando como premissa as questões epistemológicas que permeiam as relações de poder entre os sujeitos, sobretudo no que tange ao uso da língua nesse ambiente social.

Assumir tal concepção de letramento implica reconhecer que cada sujeito ou grupo social possui algum tipo de conhecimento acerca da leitura e da escrita, da utilização destas tecnologias em práticas sociais. Dessa forma, os alunos que adentram ao ambiente universitário são - e devem ser encarados - como sujeitos letrados que levam para esse espaço as concepções de leitura que construíram ao longo de suas vidas, mesmo que essas concepções não sejam sempre suficientes para que eles se envolvam de forma imediata e ativa nas práticas letradas no âmbito acadêmico.

Entretanto, ratificando a direção que aqui defendemos, ressaltamos que os três modelos não são excludentes, mas são complementares, especificamente quando se vislumbram práticas nas diversas disciplinas, na universidade, que enfatizam a importância do ensino e aprendizagem de leitura e de escrita. O aluno, ao operacionalizar os modelos referendados, promove uma réplica ativa do interlocutor, bem como da função retórica do texto, dos sentidos constituídos para a temática e do emprego de traços específicos da língua, além dos 'padrões discursivos' que são necessários à atividade de leitura.

Tal operacionalização possibilita ao aluno saber, por exemplo, como lidar com ideias 
isoladas, emergentes de um fluxo de pensamento, articulando-as de forma coerente para alcançar os objetivos que a situação comunicacional requer. Isso pode tanto se relacionar a um texto acadêmico quanto à apresentação oral de um seminário, por exemplo.

Há, ainda, a necessidade de fazer com que o aluno universitário perceba essa mudança de gênero textual que é incidente, de forma natural, em uma mudança nas formas de expressão tanto escrita quanto oral. Essas razões levam a entender que a universidade deve centrar sua atenção em um processo de ensino-aprendizagem que amplie a democratização da construção de sentidos nas atividades acadêmicas que são pertinentes à produção de conhecimento no âmbito universitário. Essa atenção torna-se marcante em teorias que ressaltam a necessidade de que os professores olhem de forma mais atenta ao ensino, fato que capacita substancialmente os professores para identificar e avaliar a amplitude dos sentidos que se expressam nas atividades distintas e dos gêneros a elas atrelados.

Diante do exposto, verificamos que a abordagem do Letramento Acadêmico compreende os letramentos como múltiplos e inteiramente relacionados com práticas sociais e, nessa abordagem, constituem o agir da academia e compõem uma forma responsiva de compreender, de interpretar e de estruturar os saberes.

Com relação à presente pesquisa, a compreensão de Letramento Acadêmico, em sua dimensão social e no âmbito universitário, tornou-se essencial na medida em que a prática de leitura que investigamos se concentra nos sentidos que os sujeitos-leitores conferem à leitura, desde os assuntos gnosiológicos, até as relações de poder entre universidade, docentes e discentes e as identidades sociais de cada um, como será verificado na seção das análises.

\section{Metodologia: os passos percorridos}

Este estudo 4 foi realizado na Universidade Federal do Tocantins, com alunos do curso de Letras - Língua Portuguesa e Respectivas Literaturas, e participantes do Programa de Apoio ao Discente Iniciante - PADI. O Programa de Apoio ao Discente Ingressante (PADI) é um programa de tutoria criado pela Pró-Reitoria de Graduação (PROGRAD), com o objetivo de auxiliar os estudantes ingressantes que estejam matriculados nos primeiro e/ou segundo período(s) e aqueles reprovados nas disciplinas básicas curriculares.

Dessa maneira, para alcançar o objetivo proposto, a coleta de dados foi realizada por meio do seguinte instrumento (ou método): técnica do PAG, que é um evento social de leitura definido por Zanotto (1995) como "uma prática colaborativa em grupo". O PAG é uma vivência pedagógica e um instrumento de geração de dados, isto é, uma prática híbrida. Ou seja, o PAG é compreendido pelos pesquisadores que o utilizam como um instrumento metodológico de

\footnotetext{
${ }^{4}$ Pesquisa aprovada pelo Comitê de Ética e Pesquisa (sob parecer no 2.478 .352 ) da Universidade Federal do Tocantins.
} 
coleta de dados e um evento de letramento que permite aos sujeitos participantes da atividade de leitura expressarem oralmente as múltiplas interpretações acerca do gênero lido.

Assim, analisamos o desenvolvimento do Letramento Acadêmico das participantes (a partir das leituras reflexivas e críticas das participantes) e o gerenciamento da professora como agente letrador por meio da vivência do PAG, com o texto "A interdisciplinaridade como método de ensino ${ }^{5}$ ", de Lilian Luitz ${ }^{6}$. Esse texto foi escolhido para a vivência porque as participantes da pesquisa, na disciplina de Estágio Supervisionado, estavam discutindo o tema interdisciplinaridade 7 , em uma perspectiva teórica para o contexto escolar.

A análise dos dados apoiou-se em uma perspectiva interpretativista de pesquisa e nos sentidos coconstruídos pelos sujeitos que participaram do evento do PAG. Outrossim, essa abordagem possibilitou investigar o letramento acadêmico levando-se em consideração os conceitos teórico-metodológicos, modelos, eventos e práticas de letramento (STREET, 2003; 2014).

Portanto, para compreendermos a constituição do Letramento Acadêmico das participantes da pesquisa por meio da mediação e do gerenciamento do professor, levamos em consideração os sentidos construídos e coconstruídos que evidenciaram um agir crítico em relação ao texto, às vozes dos interlocutores e à voz da docente.

\section{Análise e discussão dos dados: o professor universitário no desenvolvimento do letramento acadêmico}

Nesta seção, analisamos alguns recortes ${ }^{8}$ da vivência com o texto "A interdisciplinaridade como método de ensino", do Pensar Alto em Grupo, que são relevantes e que possibilitam chegar a conclusões que respondam aos objetivos deste estudo. Nessa etapa, analisam-se os posicionamentos dos participantes, as negociações que possibilitam a construção de um sentido significativo durante a prática dialógica do letramento Pensar Alto em Grupo.

\footnotetext{
5 Texto extraído de: http://www.gazetadopovo.com.br/opiniao/artigos/a-interdisciplinaridade-comometodo-de-ensino-3qbajpn16gvswxo74krvlyaqk.

6 Lilian Luitz é psicopedagoga especialista em Desenvolvimento Pessoal e Familiar e é gerente do Colégio Sesi.

7 Salientamos que a interdisciplinaridade escolar, discutida nesta análise, é diferente da Interdisciplinaridade na pesquisa científica, pois como afirma Lenoir (1998, p. 48): "[...] a interdisciplinaridade escolar trata das "matérias escolares", não de disciplinas científicas. Mesmo se as matérias escolares tomam certos empréstimos às disciplinas científicas, não constituem cópias de maneira alguma, tampouco resultam de uma simples transposição de saberes eruditos [...]".

8 Destacamos que todas as respostas que serão apresentadas a partir de agora foram transcritas literalmente, conforme as participantes responderam.
} 
A professora-pesquisadora inicia a prática de letramento do PAG apresentando o texto a ser discutido e fazendo um questionamento que possibilitou o início das discussões ([...] $o$ que vocês acharam da leitura?). Essa ação permitiu que as participantes iniciassem a interação verbal, expondo suas impressões acerca do texto. Especialmente no tocante às palavras de Luciana (achei estranho o... primeiro parágrafo né? ... eu tiraria ele (...) sobre esse "pósverdade" esse termo... ah... eu achei que ficou um pouco estranho... na minha leitura pelo menos ah:: o casamento aí...L, percebemos um agir reflexivo acerca do texto lido. Essa postura configura-se como uma etapa para a leitura crítica, além disso, é uma postura que se espera de estudantes universitários.

O posicionamento de Luciana, que é inicial e pode ser revisto no decorrer da leitura, representa uma avaliação ("eu tiraria ele [...] sobre esse "pós-verdade" esse termo...,") em relação à composição do texto no que se refere à coerência, como foi questionado pela professora-pesquisadora (da coerência? ) e respondido por ela ("eu acredito que daria para tirar ele sem prejuízo no texto"). Ao afirmar a subtração do parágrafo inicial, Luciana trouxe para a discussão um conhecimento adquirido anteriormente, nos encontros de formação promovidos pela professora-pesquisadora, enquanto coordenadora do PADI. Nesse encontro de formação (os monitores do PADI são preparados pela coordenadora, para depois realizarem atendimento aos tutorandos), foram discutidos elementos de textualidade, o que possibilitou Luciana conceber a primeira impressão acerca do texto lido, isto é, sugerir a exclusão do primeiro parágrafo.

Essa inter-relação entre os saberes anteriores - os conhecimentos de mundo - e as informações possibilitadas pelo texto-autor permitem ao sujeito-leitor maior engajamento na construção de sentidos. Esse engajamento foi se consolidando ao passo que as participantes iam se posicionando de maneira reflexiva no decorrer da construção das múltiplas leituras.

Continuando sua leitura, Luciana, de imediato, fez uma transposição da temática para o contexto brasileiro ("o exemplo que ela colocou aí da Finlândia... de como trabalhar essa interdisciplinaridade... eu pensei no aulão que geralmente se faz ... aqui no Brasil"'), ou seja, ela trouxe a questão da interdisciplinaridade para o seu contexto sociocultural. Esse posicionamento, de certa maneira, remete-nos a um sujeito-leitor-responsivo (reaçãoresposta, BAKHTIN, 1979), que não se limita apenas à superfície textual - é uma leitora reflexiva e crítica.

Seguindo o mesmo percurso para uma reflexão crítica, Daniela indaga o projeto da interdisciplinaridade na prática ("Porque eu também fiquei pensando assim... achei tudo MUito incrível... muito bom... mas será que na prática dá certo? Como é que funciona isso na prática?"). Aqui, tanto Luciana, quanto Daniela começaram a demarcar uma postura reflexiva e crítica, quando situam seus discursos nas suas próprias realidades, suas experiências.

Notamos, ainda, que os questionamentos de Daniela, de certa forma, foram um convite para a discussão da temática, permitindo um novo direcionamento na construção dos sentidos. Tal ação nos leva a afirmar que, na prática do PAG, além do professor, os próprios 
participantes podem mediar a discussão, rompendo com o "velho paradigma" de que o professor é autoridade máxima na interpretação e na condução das discussões na sala de aula. A relação professor-aluno não deve ser uma relação autoritária, de imposição, mas, sim, uma relação de cooperação, de respeito e de crescimento. Nessa relação, o professor deve considerar também os conhecimentos adquiridos anteriormente pelo aluno, sua bagagem cultural e intelectual, para a construção da aprendizagem.

Assim, Luciana, respondendo ao questionamento de Daniela, afirma que a interdisciplinaridade, proposta pela educação da Finlândia, pode não ser aderida pelos professores, pois muitos não estão dispostos a ressignificar suas práticas ("como acontece na Finlândia... [...] que as aulas não são separadas por disciplinas... é claro que éh::: um tema bastante discutido... também esse ensino interdisciplinar nem todo professor abraça"). Além de os professores não aceitarem, segundo Luciana, esse projeto interdisciplinar proposto na Finlândia, eles acreditam que não dará certo em todos os contextos ("Não dá certo em todos os contextos... tem que se pensar isso..."), porém ela enfatiza que o projeto é uma boa iniciativa para o processo de ensino-aprendizagem ("é claro que é uma ideia MUlto boa").

Refutando o posicionamento de Luciana, Daniela afirma que o projeto interdisciplinar proposto na Finlândia pode dar certo, se considerado na perspectiva da Didática ("Mas pro ponto de vista da didática eu acho que dá certo sim..."). Ela aponta uma possibilidade para tal projeto dar certo, que é trabalhar com práticas contextualizadas ("trabalhar com a contextualização é a CHAVE..."). Os deslocamentos promovidos por Daniela e Luciana, pelas tomadas de decisão, são significativos para uma atitude ativa e crítica na construção dos sentidos, bem como para o desenvolvimento do Letramento Acadêmico. Além disso, como afirma Geraldi et. al. (2002), não existem dialogismos concretizados sem os significativos deslocamentos de posicionamentos, visto que, nessa ação, é necessário que ocorra uma compreensão responsiva, rica pela abalroação propícia "[...] do encontro de consciências equipolentes" (p. 16).

Percebemos, nesses posicionamentos, uma concepção bakhtiniana que defende que, em todo enunciado concreto (o texto), o outro apresenta-se com suas contrapalavras. Assim, posicionando-se acerca da temática discutida, Adriana afirma que o trabalho interdisciplinar depende do professor ("Eu acho assim trabalhar interdisciplinaridade vai muito do professor") e acrescenta à discussão uma outra temática, ou, melhor dizendo, uma outra problemática para a execução de um projeto interdisciplinar no contexto brasileiro. Ela aponta a questão do relacionamento interpessoal e a importância do trabalho em equipe ("porque ele tem que ter um relacionamento com o outro professor para dar certo... se eles não conseguirem trabalhar em equipe...") para efetivação de uma prática interdisciplinar.

Esse processo dialógico (refutando, acatando ou acrescentando novas ideias) permite aos participantes uma compreensão responsiva, a reformulação de sentidos, a construção de significações e o avanço das interpretações. O avanço nas leituras demonstra deslocamentos de concepções - quando as participantes fazem analogias com o contexto brasileiro -, 
aplicação a outras áreas, enfim, elas apresentam respostas, demonstrando o início de uma prática responsiva, pois, no plano da responsividade, os sujeitos são dotados de respostas.

Diante das representações construídas nos turnos iniciais das vivências, principalmente por Adriana (Eu acho assim trabalhar interdisciplinaridade vai muito do professor porque ele tem que ter um relacionamento com o outro professor para dar certo...), a professorapesquisadora achou oportuno questioná-las acerca de como funciona a interdisciplinaridade na prática (Como funciona a interdisciplinaridade?). A partir do questionamento, Luciana indagou: "ou como deveria funcionar"; essa indagação foi dita em tom irônico, dando a entender que a interdisciplinaridade, na prática, pode não funcionar. Essa atitude de Luciana demonstra uma reflexividade acerca do atual cenário educacional, visto que a prática docente no Brasil é cercada de vários desafios que existem desde a formação inicial, e muitos docentes não estão preparados para trabalhar com tal perspectiva.

É pertinente observar a importância do questionamento realizado pela professorapesquisadora, assumindo uma postura de agente letrador, pois, a partir de tais perguntas, os alunos são levados a terem posicionamentos que ultrapassam os limites do texto, relacionando a temática com assuntos do seu contexto sócio-histórico. Além disso, vale ressaltar que as indagações são ferramentas significativas na coconstrução de significações ou raciocínio coletivo e possibilitam uma reflexão acerca da temática; a partir das indagações, as participantes posicionaram-se de maneira que a ideia de uma era complementada pela ideia da outra ("Acho que é assim, é você trabalhar todas as disciplinas" - ADRIANA; "Não trabalhar isoladamente" - DANIELA; "Mas no contexto... Tudo junto... uma seguindo a outra... uma dentro da outra" - ADRIANA).

Dialogando com a perspectiva freiriana, Adriana ("trabalhar todas as disciplinas; Mas no contexto... Tudo junto") e Daniela ("Não trabalhar isoladamente") afirmam que a interdisciplinaridade possibilita um trabalho, na sala de aula, dialógico e contextualizado. $\mathrm{Na}$ concepção de Paulo Freire (1987), a interdisciplinaridade é um processo teórico-metodológico de construção de saberes/conhecimentos pelo indivíduo que deve partir do seu contexto sociocultural. Por meio da interdisciplinaridade, busca-se a caracterização de dois fenômenos dialógicos: a problematização do contexto, pelo qual se revela a realidade, e a sistematização dos saberes de maneira integrada, e não isolada ou fragmentada.

Com as perguntas: "Vocês conseguem vislumbrar isso na prática? Como seria na prática? Essa interdisciplinaridade?", buscamos ativar os conhecimentos prévios, textuais e enciclopédicos das participantes, considerando que a temática tem relação direta com a atuação delas enquanto futuras professoras de Línguas. Nas palavras de Santos (2014, p. 141), "[..] o ato de perguntar e responder é um processo que oportuniza a construção do conhecimento e da reflexão, contribuindo, assim, para a aprendizagem do aluno" ou, pode-se dizer, por meio dos questionamentos, a agente letradora promove situações mais reflexivas, exigindo posicionamentos críticos e legítimos das participantes. Esses posicionamentos possibilitarão o desenvolvimento do Letramento Acadêmico, já que essas participantes agem 
de maneira responsiva.

Luciana, como resposta ao questionamento da professora-pesquisadora, afirma que, na prática, consegue perceber a interdisciplinaridade no ensino e na aprendizagem da literatura e da gramática (Eu sei que acontece muito de literatura e gramática... mas aí já é dentro da língua portuguesa...); porém, Daniela questiona como realizar tal movimento nas disciplinas de Português e Matemática ("Mas pensar em português e matemática, como fazer?"), o que nos leva a inferir que, para ela, não é possível tal articulação. Assim, como forma de compreender e redirecionar a resposta de tal questionamento, para que as próprias participantes refletissem e construíssem sentidos, a professora-pesquisadora questiona se não é possível tal realização (Não tem como?).

Essa ação possibilitou aos sujeitos envolvidos maior interação com os saberes apreendidos na formação inicial e os saberes construídos durante sua trajetória. As participantes Adriana e Luciana assumiram uma posição legítima na argumentação e na defesa de um ponto de vista, em que esta ratifica o posicionamento daquela ("Tem como SIM... a interpretação dos problemas", ADRIANA; "Se o aluno não consegue interpretar... se ele faz uma leitura errada não pense que ele vai ter uma resposta certa daquele problema", LUCIANA). Percebemos, aqui (fala de Luciana), que os argumentos são a maneira pela qual explicamos e defendemos um ponto de vista. Nesse jogo dialógico, as participantes relacionaram teoria e prática de modo que aquela se una a esta no processo de compreensão do sentido da movimentação que define as mudanças e as permanências dos processos sociais.

As reflexões trazidas pelas participantes demonstraram um princípio norteador do projeto da interdisciplinaridade, que é a não fragmentação do saber, pois este projeto é um "movimento" articulador do processo de ensino e aprendizagem (FAZENDA, 1979). Além disso, a interdisciplinaridade assume, na construção do conhecimento, uma concepção mais integradora, dialética e totalizadora na construção do conhecimento e da prática pedagógica.

De acordo com os estudos acerca da compreensão leitora (KATO, 2002; KLEIMAN, 2013a, 2013b; SOLÉ, 1998), nota-se a importância do professor letrador no processo do desenvolvimento do Letramento Acadêmico - como negociador dos sentidos entre as participantes - e a necessidade do desenvolvimento de estratégias de leitura para atingir esse objetivo. Com o questionamento realizado pela professora-pesquisadora (Como eu poderia trabalhar esse tema em escrita acadêmica? Em morfologia do português? Um exemplo... como eu poderia trabalhar isso aí na disciplina de sintaxe?... teria como?), a participante Luciana respondeu com segurança que é possível realizar um trabalho com interdisciplinaridade, partindo do pressuposto de que "a interdisciplinaridade tenta superar a fragmentação $e$ dicotomias existentes na educação escolar disciplinar" (LUCIANA).

Luciana, ainda em seu discurso, demonstra uma postura que dialoga com o modelo de Letramento Acadêmico proposto por Lea e Street (2014), que Ihe permitiu a aproximação ou o afastamento do texto lido, pois, ao considerar as ações que são possibilitadas por um ensino pautado na interdisciplinaridade (aproximação do texto lido), segundo ela, o professor assume 
um papel de pesquisador, atualizando seu conhecimento (afastamento do texto lido) - " $A$ interdisciplinaridade leva o professor a buscar mais, a pesquisar...".

Considerando a resposta de Luciana, a professora letradora indagou-a acerca de como seria um trabalho interdisciplinar (Qual seria por exemplo um trabalho interdisciplinar?). Esse questionamento ativou uma postura que, até os dias de hoje, perdura nas atividades de leitura, isto é, uma leitura pautada em uma perspectiva autoritária, em que os leitores têm receio de falarem sobre suas interpretações, temendo estar fugindo do que é "esperado" pelo professor enquanto autoridade interpretativa (“Pensei aqui mas já tava fugindo"... LUCIANA).

Como forma de legitimar a voz de Luciana, demonstrando que sua leitura é importante independentemente de "estar fugindo" ou do esperado pelo professor, a professora letradora convida-a a manifestar sua leitura (Mas, podes falar assim mesmo...). Essa postura está em conformidade com o princípio básico do PAG, que é dar voz aos sujeitos-leitores. Assim, ao assumir essa postura, a professora letradora rompe com a crença de que o professor é "autoridade máxima interpretativa" na prática de leitura, dando lugar para um ambiente dialógico e responsivo para construção de sentidos pelos sujeitos-leitores. Além disso, essa atitude promove o fortalecimento da voz, da subjetividade e da identidade do leitor, dialogando com o modelo da socialização acadêmica proposto por Lea e Street (2014).

Com a voz valorizada pela professora letradora, Luciana expõe sua leitura - que antes acreditava estar fugindo - exemplificando a questão da escrita do professor ("Não porque eu ia pensar a questão da própria escrita desse futuro professor, né?"). Para a participante, o professor deve ser pesquisador e ler de forma contínua para que possa ter uma escrita proficiente ("para escrever ele precisar ter o hábito de pesquisar, né? Ler muito... o professor não deve só pensar em sua disciplina, deve ir além..."). Essa leitura dialoga com o que é defendido no projeto interdisciplinar, pois o saber não deve ser 'fragmentado em disciplinas'. É necessária, como sustentado por pesquisadores da área, dentre eles Ivani Fazenda (1979), uma atitude interdisciplinar do professor, na investigação constante de apropriação teórica e, principalmente, no papel ético perante as problematizações que envolvem o conhecimento.

Dando continuidade à sua postura de agente letradora, a professora-pesquisadora, por meio de questionamentos, busca compreender as leituras das participantes acerca da interdisciplinaridade como "método" e se tal projeto é visto pelas participantes como algo positivo ou negativo ("Então vocês veem a questão da interdisciplinaridade como um método, né? Isso algo visto de maneira positiva ou negativa?"). Adriana, de imediato, responde que, segundo o que é explicado no texto - ela busca no texto-fonte argumentos para seu posicionamento -, a interdisciplinaridade é compreendida como um "método" positivo ("Segundo o texto de maneira positiva, né?"). Dialogando com essa perspectiva e justificando tal posicionamento, Luciana afirma que tem tudo para ser positivo quando esse projeto é pensado de maneira coletiva; pois, nas palavras dela:

Tem que ter essa discussão dos pontos de vista entre os professores pra 
mostrar várias possibilidades do uso daquele tema para os próprios alunos... e fazerem eles pensarem criticamente. Então... ahnn partir só do professor de escrita acadêmica?... tá agora eu vou trabalhar a interdisciplinaridade... vou pensar lá na didática... sem esse diálogo com o professor de didática eu acho que... não. Que não fosse funcionar. Mas talvez perdesse o sentido e aí descaracteriza essa interdisciplinaridade... No meu pensamento ela não vai acontecer só com um professor... [...] Aquele outro professor e aquela outra disciplina é que vai conversando comigo é com diálogo que nós vamos chegar a um projeto interdisciplinar... (LUCIANA).

Koch e Elias (2006, p. 19) asseveram que "a constante interação entre o conteúdo do texto e o leitor é regulada pela intenção com que se lê o texto, pelos objetivos da leitura". A leitura de Luciana permite dizer que a produção do sentido na atividade de leitura não fica retida na superfície textual, todavia tem essa superfície como "meio" para se chegar à compreensão responsiva. Segundo a participante, é necessário que todos os saberes dialoguem, porque só assim poderemos chegar ao projeto interdisciplinar. Além disso, ela deixa evidente, em seu discurso, marcas de um posicionamento pessoal, isto é, sua voz e subjetividade acerca do texto lido ("No meu pensamento"). Ainda, no discurso de Luciana, é possível notar que ela pensou nas implicações da interdisciplinaridade no contexto brasileiro.

Dessa forma, sendo significativamente influenciada pela resposta de Luciana, que defende a necessidade de um diálogo entre os professores para que o ensino pautado na interdisciplinaridade dê certo, de maneira instantânea, a professora-pesquisadora fez uma intervenção ("Vocês tiveram a mesma leitura que a Luciana? Concordam? Querem complementar?"), buscando o posicionamento das demais participantes. Luciana (Podem discordar também... tem problema não.) imediatamente complementa a intervenção, asseverando que as demais participantes podem discordar dela, o que demonstra uma atitude responsiva e necessária no desenvolvimento do Letramento Acadêmico.

A participante, ao proferir "podem discordar também... tem problema não", aponta uma ação de um leitor responsivo ativo em uma situação dialógica de coconstrução de sentidos. Luciana ratifica que o processo de compreensão leitora compõe-se de uma atividade interacionista, que não é realizado apenas por "concordâncias", mas também por "discordâncias" que se complementam na construção das múltiplas leituras. A participante, ao utilizar a expressão "discordar", que, segundo Pontecorvo (2005, p. 58), é "[...] sempre um segundo elemento em um par de turnos e que não é um movimento 'preferido' [...]", ratifica a liberdade de expressão de cada participante, que é possibilitada durante a realização do Pensar em Alto em Grupo.

Nos argumentos das participantes, notamos uma interação que se configura em concordâncias adicionadas às novas reflexões. Daniela concorda com Luciana, porém acrescenta informações que levam a outro ponto a ser discutido, o acréscimo de "trabalho" para o professor ("Eu concordo... mas eu vejo assim como método que poderá exigir mais do professor..."). Por sua vez, Luciana (Exato... e pelo fato de ele não dominar todas aí é que... 
mas...) afirma que esse acréscimo possibilitará uma mudança significativa na prática docente, uma vez que o professor superará a "dicotomia ensino x pesquisa".

Ainda, a participante complementa que, com a utilização do projeto interdisciplinar, o professor terá um conhecimento amplo e suas aulas serão mais interessantes, pois os alunos estariam mais estimulados a "prestarem atenção na aula" ("Seria muito enriquecedor e é como ela coloca né que tornaria as aulas interessantes... aí você não teria os alunos todos com os celulares viajando em outro mundo").

Percebendo, dessa forma, a participação responsiva das participantes, a professorapesquisadora continua sua postura de agente letradora e realiza questionamentos com a finalidade de promover a coconstrução dos sentidos dos leitores. Para tanto, ela utiliza trechos do texto para que as participantes fundamentem suas leituras no mesmo, percebendo que ele é um elemento intermediário para construção de sentidos lido (Mas quando você ver... porque se você vai olhar né? essa pós-verdade nessa questão da influência do outro... olha bem no subtítulo aí?).

A professora letradora, por meio dos questionamentos, permite que as participantes compreendam a voz da autora por intermédio do texto. Para tanto, ela cita "partes" específicas do texto para que as participantes discutam (olha bem no subtítulo aí? "Métodos interdisciplinares e contextualizados incitam o pensamento crítico privilegiam o conhecimento global e trazem outras inúmeras vantagens"?). Com os questionamentos, as participantes são estimuladas à reflexividade, que, segundo Zanotto e Sugayama (2016), pode ser vivida e aprendida na prática do PAG.

Na reflexividade, a inter-relação entre o eu e as outras vozes é valorizada e fortalecida por meio das leituras (discussões) coletivas. Luciana, respondendo ao questionamento da pesquisadora ("Métodos interdisciplinares e contextualizados incitam o pensamento crítico privilegiam o conhecimento global e trazem outras inúmeras vantagens"?), traz ideias da autora para sustentar seu argumento ("Fora da escola... talvez seria a questão de ele não beber só dessas fontes, por exemplo lá das redes sociais baseados só no/na/nos apegos à emoção e às crenças pessoais, né?"). Dessa forma, dialogando com as ideias da autora, para Luciana, no processo de ensino e aprendizagem, a construção do conhecimento deve ultrapassar os limites do contexto escolar, o que ela denomina de "globalização do conhecimento".

Mais uma vez, a professora letradora, privilegiando a interação - e pensando com o grupo - das leitoras com a autora, bem como a legitimação da voz de Luciana ("É necessário ir além dos limites da sala de aula, não fragmentar o conhecimento. Pensar, como você disse Luciana, numa perspectiva globalizada"), faz uma pergunta acerca de uma afirmação da autora ("O que autora diz aqui"). E respondendo ao questionamento, Luciana diz que os "fatos objetivos" não influenciam na concepção de conhecimento dos sujeitos. A participante apresenta trecho do texto fonte que a levou a essa interpretação ("Que coloca aí... eles têm menos influência/importância na concepção do conhecimento das pessoas...").

A leitura de Luciana e as provocações (questionamentos) da professora letradora 
deram espaço para entrar em cena a voz de Adriana que, diferentemente de Luciana, não buscou fragmentos do texto base para sustentar seu posicionamento. Adriana, a partir do que foi exposto pela professora-pesquisadora e por Luciana, afirma que levar a teoria para prática, isto é, transpor didaticamente os conhecimentos teóricos para o contexto do aluno é um trabalho complexo para o professor ("Isso que acho, assim para nós professores, é muito difícil/complexo é você () na sala de aula trabalhar assuntos do cotidiano..."). Para Adriana, muitas vezes, no Ensino Médio, são trabalhados conteúdos que ela, enquanto estudante, não usou em sua vida cotidiana ("O que acontece muitas vezes no Ensino Médio são temas tão fúteis, que eu não usei isso na minha vida [...]").

O professor, na função de agente letrador, deve considerar o leitor e seus conhecimentos, reconhecendo que esses conhecimentos são diferentes de um leitor para outro, o que implica aceitar as múltiplas leituras e os múltiplos sentidos em relação a um mesmo texto. Em relação a esta vivência, podemos dizer que as discussões trilharam caminhos nos quais as participantes puderam manifestar seus pontos de vista e desenvolverem a argumentação.

Como forma de influenciar a participação das alunas nas discussões, a agente letradora faz o seguinte questionamento: "Mais alguma coisa em relação ao texto?". Essa indagação possibilitou um posicionamento crítico da participante Luciana, que afirmou que o trabalho com a questão da interdisciplinaridade na sala de aula requer, primeiramente, o "apagamento de ego de muitas pessoas". A participante ressalta, ainda nesse turno, que o seu posicionamento se refere a um contexto social experienciado por ela ("pelo menos na realidade que eu conheço NÃO"). Esse fato implica uma atitude responsiva, pois a participante dá margem para seus interlocutores posicionarem-se também em relação ao tema discutido, podendo ser posicionamentos diferentes do dela.

Esse posicionamento responsivo leva a outra problemática que permeia a esfera universitária que é a "vaidade acadêmica". Não se pode negar que trabalhar com a produção do conhecimento confere a alguns sujeitos um sentimento de poder ${ }^{9}$ que dificulta a interação com outros colegas, ou, até mesmo, compartilhar os conteúdos trabalhados de modo a que exista uma interação entre os docentes.

Ao serem questionados pela professora-pesquisadora (Vocês concordam com a Luciana? Ou tiveram outra leitura?) sobre se concordam com o posicionamento de Luciana, Adriana prontamente respondeu que é relativo tal posicionamento, porque depende do perfil do professor, ou seja, nem todos os docentes dispõem-se a um trabalho interdisciplinar, por considerá-lo mais dispendioso ("vai do professor mesmo da disponibilidade dele de querer trabalhar dessa forma... que é uma forma que dá mais trabalho exige mais").

Um fato interessante que se verificou nas ações da professora-pesquisadora foi a

\footnotetext{
9 "Não devemos nos enganar: se falamos do poder das leis, das instituições ou das ideologias, se falamos de estruturas ou mecanismos de poder, é apenas na medida em que supomos que 'alguns' exercem um poder sobre os outros" (FOUCAULT, 1995, p. 40).
} 
utilização de perguntas diretas (Vocês concordam com a Luciana? Ou tiveram outra leitura?; $E$ aqui no Brasil? Não tinha como dá certo?; Mas na vivência de vocês/vocês não lembram de nenhum professor que tenha trabalhado ou tentado trabalhar dessa forma?). Essas perguntas favoreceram a construção de novos posicionamentos e a contraposição de pontos de vista. Luciana faz uso de argumentos ("você disse que pegou o texto que um outro professor, passou de uma outra disciplina e aproveitar para aprofundar, e trabalhar a sua disciplina...") retomando até o que a professora-pesquisadora disse em turnos anteriores - para ratificar seu posicionamento quanto às atitudes dos docentes em relação ao jogo de "egos", que ela remete à questão de rivalidade ("não acontece sempre assim com facilidade propor isso para... não é todo mundo que vai abraçar não...não é porque já vai entrar em outro tema que é a questão da rivalidade de egoísmo que existe sim... não só nessa profissão mas tem professor que acredita que a sala é dele").

O processo de coconstrução vislumbrado na fala de Luciana permitiu que ela retomasse explicitamente a fala anterior da professora-pesquisadora, com a intenção de acrescentar e de ratificar seu ponto de vista. Além disso, esse fenômeno é denominado por Pontecorvo (2005, p. 78) como opositivo-argumentativo. Nas palavras da autora, o aspecto significativo desse processo "é quando um dos interlocutores opõe-se ou põe algo em questão no discurso, provoca uma argumentação mais profunda e produz análises mais acuradas do problema".

Dando continuidade às discussões, a professora-pesquisadora possibilitou que as participantes se apropriassem e compreendessem a temática discutida no texto e desenvolvessem o conhecimento em um ambiente sócio-histórico situado, o Brasil. Com essa atitude, a professora letradora permitiu um (re)pensar acerca das realidades particulares de cada participante. Essa prática é defendida pelos Novos Estudos do Letramento - NEL, pois possibilita maior aproximação dos problemas que afetam a realidade dos sujeitos envolvidos. Além disso, ao assumir tal posicionamento, a professora-pesquisadora permite emergir não somente novas conjunturas e ambientes de aprendizagem, como também a necessidade de uma flexibilização no plano das atividades que compõem os contextos de ensino e de aprendizagem.

Observa-se, na atitude da agente letradora, características próprias do sujeito que, nas palavras de Kleiman (2007, p. 21), “[...] é capaz de articular interesses partilhados pelos aprendizes, organizar um grupo ou comunidade para a ação coletiva, auxiliar na tomada de decisões sobre determinados cursos de ação". Constatamos, dentro desse contexto, que as práticas de letramento são fenômenos complexos, que indicam uma direção e o estabelecimento dos sujeitos caracterizados pela historicidade, por fatores sócio-históricopolítico-culturais. Assim, o letramento ultrapassa meras competências técnicas em relação à leitura e à escrita, ele é entendido, como dito em seções anteriores, como "um conjunto de práticas sociais, observáveis em eventos mediados por textos" (BARTON; HAMILTON, 2000, p. 8, tradução nossa).

Na prática do PAG, a postura da agente letradora permitiu às participantes uma 
argumentação que ora se opõe, ora dialoga. Essa dimensão opositiva contribuiu significativamente no avanço do "discurso-raciocínio" (PONTECORVO, 2005), permitindo embasamento (Vocês concordam com a Luciana? Ou tiveram outra leitura?) e aprofundamentos. Adriana ultrapassa os limites do texto, trazendo para a discussão nova temática, questões importantes que afligem o profissional do ensino, que é a questão da desigualdade na profissão docente ("Que é assim a desigualdade no Brasil é tão complexa que até dentro da própria profissão... por exemplo tem gente que acha que professor de português é mais importante que professor de artes...").

Compreendemos que, independentemente da área assumida pelo docente, seu papel é fundamental no processo de ensino e aprendizagem, não como simples possibilitador de saberes, mas como negociador e gerenciador de sapiência ou de conhecimento, apreciando a prática empírica e o saber intrínseco de seu discente na procura de seu desenvolvimento e formação como sujeito pensante, criativo, crítico e responsivo, assim como da formação de sua cidadania.

A agente letradora, no intuito de mediar a relação ativa entre as participantes e o contexto sócio-histórico-cultural, profere um questionamento ("Mas na vivência de vocês... não lembram de nenhum professor que tenha trabalhado ou tentado trabalhar dessa forma interdisciplinar? ...") com a finalidade de ativar os conhecimentos anteriores, a experiência e os sentidos construídos no decorrer de suas vidas acadêmicas, acionando também seus potenciais cognitivos, suas capacidades e interesses e seus procedimentos de pensar, ou seja, suas experiências pessoais.

Com esse questionamento, Luciana ratifica sua leitura anterior ("Agora no momento eu não lembro... eu sempre tive essa visão mesmo que acabei de colocar aqui... é muito ego né?"), retomando a questão do ego dos docentes. A partir dessa resposta e buscando resgatar a participação das demais participantes, bem como saber a leitura das outras participantes, a professora letradora pergunta: “E vocês meninas, nunca tiveram?”

Essa postura da professora letradora evidencia que nem sempre, em uma prática de leitura, todos os participantes envolvem-se ativamente; às vezes, é necessária uma atitude de mediação, como demonstrado pela pesquisadora ao convidar as outras participantes a colaborarem com a construção do sentido.

Percebemos, na vivência, uma das funções da agente letradora, que é negociar sentidos. Ratifica-se a importância dos questionamentos para mediar a atividade de leitura; eles são ferramentas significativas para a negociação da constituição das significações pelos participantes, bem como para a continuidade do processo de leitura. $O$ ato de questionar e de responder oportuniza um desenvolvimento efetivo da coconstrução do raciocínio coletivo, da construção de conhecimento, possibilitando a aprendizagem e a apreensão de saberes pelos leitores.

A agente letradora, em uma atitude de negociadora dos sentidos (Por exemplo... qualquer outra disciplina que vocês tiveram né?; $E$ vocês acham assim... essa atividade foi 
produtiva?), questiona se outras participantes não vivenciaram, na UFT, um trabalho interdisciplinar. Essa atitude demonstra a importância das relações dialógicas na construção do sentido, pois o professor, ao fazer tal questionamento, possibilitou uma abertura para um diálogo profícuo e crítico entre as participantes, não dando margem a interpretações homogêneas - o que vai de encontro à concepção monológica de leitura. Nas palavras de Freire (2007),

[...] o diálogo é uma exigência existencial. E, se ele é o encontro em que se solidarizam o refletir e o agir de seus sujeitos endereçados ao mundo a ser transformado e humanizado, não pode reduzir-se a um ato de depositar ideias de um sujeito no outro, nem tampouco tornar-se simples troca de ideias a serem consumidas pelos permutantes (FREIRE, 2007, p. 91).

Para Freire (2007), a prática do professor em uma relação significativa com os discentes promove uma dialogicidade na construção dos sentidos. Além disso, para o referido autor, quando o docente age nessa perspectiva, ele é visto como um mediador, gerenciador de conhecimento, um sujeito qualificado para sistematizar, de forma articulada, as experiências das participantes com o contexto no qual elas estão inseridas, promovendo e desenvolvendo competências específicas de um significativo letramento acadêmico.

Posteriormente ao questionamento feito, ficou explícito como as outras participantes se colocaram em relação ao posicionamento de Luciana (Agora no momento eu não lembro... eu sempre tive essa visão mesmo que acabei de colocar aqui... é muito ego né? Fulano de tal pra lá não tem nada a ver). Os relatos da participante Juliana demonstram que existem docentes que trabalham de forma "interdisciplinar" de maneira produtiva ("Sim nós tivemos...assim eu lembro que a matéria de sociologia... foi ... o professor ele trabalhou inter/um livro que era de texto narrativo"...).

Um dos exemplos de coconstrução é a retomada de discursos. Na fala de Daniela, ficou claro esse processo, quando ela retoma o discurso de Juliana ("Como Juliana disse, né? Trabalhar de forma interdisciplinar nos permite outra visão... o trabalho interdisciplinar requer mais participação, pois precisamos do conhecimento mais amplo... sempre estaremos vendo o saber como todo"). Essa prática de coconstrução contribuiu para que, no conjunto de tantas vozes, as singularidades de cada participante fossem respeitadas e colocadas na interação (foi vislumbrado esse respeito quando Luciana deixa claro que seu posicionamento se refere a uma experiência individual).

As experiências de Juliana e de Daniela foram diferentes das leituras de Luciana e de Adriana, algo comum na prática de leitura dialógica do PAG. Isso é confirmado quando a professora-pesquisadora evidencia que existiu, de certa forma, o projeto interdisciplinar na prática ("então houve prática, né? Diferentemente da Luciana e da Adriana né? Que não tiveram essa ahn:: essa experiência..."). Além disso, a professora-pesquisadora, como forma 
de explicar ou de demonstrar a importância do projeto interdisciplinar, destaca: "Por exemplo, não tem como dissociar Escrita Acadêmica de Metodologia Científica, dos conhecimentos de vocês, das experiências?". De maneira rápida, Luciana ironiza o exemplo dado pela pesquisadora, dizendo que poderia ser uma continuidade, isto é, um trabalho interacional e contextualizado (Deveria ser uma continuidade né? mas...). Buscando compreender a atitude de Luciana, a agente letradora indaga: "Como assim? Como deveria ser uma continuidade?".

Respondendo ao questionamento, Luciana afirma que "nem sempre" acontece o projeto interdisciplinar na prática. Segundo a participante, os saberes anteriores dos alunos não são considerados, pois o professor é considerado detentor do conhecimento e não admite interação com as demais áreas do saber (Nem sempre acontece... o professor nem considera $o$ que sabemos. Ele é sempre o detentor do conhecimento e não permite esse diálogo com as demais áreas.).

O processo de mediação da agente letradora, nesta vivência, é, portanto, uma intersecção que se concretiza em interação - por meio dos questionamentos - constante na construção dos múltiplos sentidos. O ambiente de discussão proporcionado pelo dialogismo constituiu um espaço complexo e, ao mesmo tempo, instigante, no que diz respeito ao reconhecimento e à importância de como a temática em si foi discutida por todos os envolvidos. A partir da resposta de Luciana, a professora letradora sugeriu que as participantes considerassem a questão da teoria e da prática (Esse diálogo, relacionando com teoria $e$ prática...), uma vez que elas estão em processo de formação. Para tanto, a pesquisadora lançou o seguinte questionamento: "Existe um distanciamento do que vocês veem na prática e vão fazer lá na escola, por exemplo no Estágio Supervisionado?".

As participantes (Adriana; Luciana; Daniela) responderam que sim, o que nos leva a inferir que, até os dias atuais, teoria e prática "caminham na contramão" do processo de ensino e aprendizagem. Essa "contramão" vai de encontro à proposta freireana, que se caracteriza em um contexto originariamente dialético. Nas palavras de Freire (1987, p. 38), é necessário que seja clarificado, que a “[...] práxis, porém, é reflexão e ação dos homens sobre o mundo para transformá-lo. Sem ela, é impossível a superação da contradição opressoroprimido".

Segundo a participante Daniela, elas não são preparadas para o mundo, como é proposto no projeto interdisciplinar ("não somos preparados para o todo, o mundo... como vimos no texto que lemos em Estágio...), o que contraria a proposta dialética de Paulo Freire. Na prática, segundo Freire (1987), o sujeito, concomitantemente, age e reflete e, ao prover uma reflexão, ele age, isto é, os sujeitos da teoria caminham para prática e dessa prática chegam à nova teoria.

Complementando e ratificando a fala de Daniela, Adriana afirma que existe um distanciamento entre teoria e prática, pois o ensino é fragmentado ("E como existe... é tudo muito fragmentado..."). Ainda, para Adriana, o que elas veem na Universidade é diferente do que é trabalhado na escola (" $E$ isso a gente não vê aqui no nosso curso... mas eu não vejo ao 
pé da letra como eu tenho que ensinar lá na escola, de maneira interdisciplinar"...), demonstrando que teoria e prática não se fazem juntas. Dessa forma, para que o ensinoaprendizagem seja realizado de maneira significativa, é fundamental que teoria e prática andem juntas, porque essa é uma premissa necessária para a emancipação e a realização humana.

Assim, compreendemos que a formação de um professor para atuar como agente letrador faz novas e diferentes exigências ao professor universitário: os saberes acadêmicos e a familiaridade com diversas práticas de letramento, inclusive as acadêmicas, são ainda importantes. Mas o essencial é a atitude de um agente letrador, que, em contínuo processo de letramento, aventura-se a experimentar e, com isso, a continuar aprendendo com seus alunos, por intermédio de práticas letradas que motivam o grupo e atendem, ao mesmo tempo, a interesses e a objetivos individuais e, assim, formam leitores e despertam curiosidades.

\section{À guisa das discussões}

Este artigo objetivou investigar a atuação do professor enquanto agente de letramento na universidade, com a finalidade de compreender de que forma este agente faz a mediação e o gerenciamento das diferentes vozes numa atividade dialógica de construção de sentidos. Logo, na vivência do PAG, constatou-se quão desafiador é lidar com todas as leituras disponibilizadas pelos participantes. Foi necessário a agente letradora pensar junto com as participantes, em um processo de negociação, para decidir juntamente com elas quais leituras podem ser aceitas ou não, com base em uma compreensão intuitiva de importância ou relevância".

Dessa forma, durante o evento de letramento do Pensar Alto em Grupo, algumas ações da professora-pesquisadora foram necessárias para que o desenvolvimento das vivências ocorresse de maneira efetiva. As ações foram coerentes com o dialogismo e o modelo da Socialização Acadêmica, como: promover questionamentos menos diretivos, de outra qualidade e em menor quantidade, com a intenção de expandir as ideias dos leitores; abrir mão do poder de autoridade interpretativa; dar voz às leitoras para que elas pudessem livremente construir as suas leituras; mediar as múltiplas leituras.

Portanto, essa atitude, por parte da pesquisadora, demonstrou uma ação efetiva de uma agente letradora, uma vez que ela mobilizou, por meio de questionamentos, saberes relevantes à realidade das participantes, bem como valorizou o contexto sócio-históricocultural das pessoas envolvidas na prática de letramento do PAG e possibilitou o desenvolvimento do Letramento Acadêmico. Assim, tanto as ações das participantes na prática de leitura dialógica foram legitimadas, quanto as da professora letradora. Durante o pensar coletivamente, as participantes, por meio da interação, expandiram suas reflexões, de maneira 
que ampliaram, refutaram ou aceitaram novos pensamentos, colocando em cena a vivência de uma ação dialógica com outros sujeitos-leitores por meio de deslocamentos.

\section{Referências}

BAKHTIN, M. [1979]. Estética da criação verbal. Tradução de Paulo Bezerra. 4. ed. São Paulo: Martins Fontes, 2003.

BATISTA-SANTOS, Dalve Oliveira. Letramento acadêmico: representações de ingressantes acerca da escrita. Revista Trama, v. 13, n. 28, p. 86-118, 2017.

FAZENDA, Ivani C. Integração e interdisciplinaridade no ensino brasileiro: efetividade ou ideologia. São Paulo: Loyola, 1979.

FIAD, R. S. A escrita na universidade. Revista da ABRALIN, v. Eletrônico, n. Especial, p. 357-369. 2. a parte, 2011. https://doi.org/10.5380/rabl.v10i4.32436

FISCHER, A. A construção de letramentos na esfera acadêmica. Tese (Doutorado) - Programa de Pós-Graduação em Linguística, Universidade Federal de Santa Catarina, Florianópolis, 2007. $340 f$.

FOUCAULT, Michel. O sujeito e o poder. In: RABINOW, P.; DREYFUSS, H. Michel Foucault: uma trajetória filosófica. Rio de Janeiro: Forense Universitária, 1995.

FREIRE, P. Pedagogia da autonomia. 36. ed. São Paulo: Paz e Terra, 2007.

FREIRE, P. Pedagogia do Oprimido. São Paulo: Paz e Terra, 1987.

GEE, J. P. Social linguistics and literacies. Ideology in Discourses. 2. ed. London/Philadelphia: The Farmer Press, 1999.

GEE, J. P. The new literacy studies: from 'socially situated' to the work of the social. In: BARTON, David; HAMILTON, Mary; IVANIC, Roz. Situated literacies. Reading and writing in context. London/ New York: Routledge, 2000. p.180-196.

GERALDI, J. W. (Org.) et al. O texto na sala de aula. 3. ed. São Paulo: Ática, 2002.

HAMILTON, M. Expanding the new literacy studies: using photographs to explore literacy as social practice. In: BARTON, David; HAMILTON, Mary; IVANIC, Roz (Org.). Situated literacies. London: Routledge, 2000. p. 56-87.

KATO, M. O aprendizado da leitura. São Paulo: Martins Fontes, 2002.

KLEIMAN, A. B. Processos identitários na formação profissional - O professor como agente de Letramento. In: CORRÊA, M.; BOCH, F. Ensino de língua: representação e letramento. Campinas, SP. Mercado das Letras, 2006.

KLEIMAN, A. B. Letramento e suas implicações para o ensino de língua materna. Signo, v. 32, n. 53, p. 1-25, 2007.

KLEIMAN, A. B. Oficina de leitura - teoria e prática. 15. ed. Campinas-SP: Pontes Editores, 2013a. 
KLEIMAN, A. B. Texto e leitor: aspectos cognitivos da leitura. 15. ed. Campinas-SP: Pontes Editores, 2013b.

$\mathrm{KOCH}$, Ingedore Villaça; ELIAS, Vanda Maria. Ler e compreender: os sentidos do texto. 2 ed. São Paulo: Contexto, 2006.

LEA, M. R.; STREET, B. V. O modelo de "letramentos acadêmicos": teoria e aplicações. Filol. Linguíst. Port., São Paulo, v. 16, n. 2, p. 477-493, jul./dez. 2014.

LENOIR, Yves et al. Didática e interdisciplinaridade: uma complementaridade necessária e incontornável. In: FAZENDA, I. C. A. (org.) Didática e interdisciplinaridade. Campinas: Papirus, 1998, pp. 45-75.

PONTECORVO, Clotilde. Discutir, argumentar e pensar na escola. O adulto como regulador da aprendizagem In: PONTECORVO, C.; AJELLO, A. M.; ZUCCHERMAGLIO, C. Discutindo se aprende: interação social, conhecimento e escola. Porto Alegre: Artmed, 2005, p. 65-88.

SANTOS, M. T. A prática de leitura do Pensar Alto em Grupo: a formação do aluno leitor crítico e a do professor agente de letramento. Tese (Doutorado em Linguística Aplicada e Estudos da Linguagem) - Pontifícia Universidade Católica. São Paulo: PUC, 2014. $251 f$.

SOLÉ, Isabel. Estratégias de leitura. Tradução Cláudia Schilling. 6. ed. Porto Alegre: Artmed, 1998.

STREET, B. Abordagens alternativas ao letramento e desenvolvimento. Teleconferência Brasil sobre o letramento, outubro de 2003.

STREET, B. Letramentos sociais: abordagens críticas do letramento no desenvolvimento, na etnografia e na educação. São Paulo: Parábola Editorial, 2014.

STREET, B. Os novos estudos sobre o letramento: histórico e perspectivas. In. MARINHO, M.; CARVALHO, G. T. (Orgs.). Cultura escrita e letramento. Belo Horizonte: Ed. UFMG, 2010.

STREET, B. Políticas e práticas de letramento na Inglaterra: uma perspectiva de letramentos sociais como base para uma comparação com o Brasil. Caderno Cedes. Campinas, v. 33, 246 n. 89, p. 51-71, jan./abr. 2013. https://doi.org/10.1590/S0101-32622013000100004

ZANOTTO, Mara Sophia. Metáfora, cognição e ensino de leitura. D.E.L.T.A., São Paulo, v. 11, n. 2, p. 241-254, 1995.

ZANOTTO, Mara Sophia; SUGAYAMA, Ariane Mieco. Um confronto heurístico entre práticas de letramento e as epistemologias do monologismo e do dialogismo. Revista Signum, Londrina, v. 1, n. 19, p. 11-39, 2016. https://doi.org/10.5433/2237-4876.2016v19n1p11

Recebido em: 05/03/2019

Aceito em: 28/06/2019 